\title{
Parking and Restarting a Molecular Shuttle In Situ
}

\author{
Nai-Chia Chen, ${ }^{[a]}$ Chien-Chen Lai, ${ }^{[b]}$ Yi-Hung Liu, ${ }^{[a]}$ Shie-Ming Peng, ${ }^{[a]}$ and \\ Sheng-Hsien Chiu*[a]
}

\begin{abstract}
Herein we report an easy-to-synthesize [2]rotaxane, which incorporates two ionic monopyridinium stations and one 2,2'-bipyridine station as the shaft of the dumbbell-shaped component and a bis- $p$-xylyl[26]crown-6 (BPX26C6) unit as the macrocyclic component. In this molecular shuttle, the BPX26C6 unit can be docked selectively on either the central 2,2'-bipyridine station or one of the two terminal pyridinium stations, and subsequently, returned to its shuttling molecular motion through the in situ addition of simple reagents (acid/base or metal ion/ metal-ion-complexing ligand pairs).
\end{abstract}

Keywords: host-guest systems molecular machines • molecular shuttles - molecular switches . rotaxanes

\section{Introduction}

Mechanically interlocked molecules attract a great deal of attention because of their potential for application in mesoscale devices and nanoscale molecular machinery. ${ }^{[1]}$ Degenerate molecular shuttles, ${ }^{[2]}$ in which macrocyclic units oscillate between symmetrical recognition sites, are commonly used as substrates for probing the dynamic behavior of these molecular machines in solution because rate data for these systems can be obtained readily through the use of dynamic ${ }^{1} \mathrm{H}$ NMR spectroscopy. ${ }^{[3]}$ For molecular shuttles to exhibit behavior more suitable for use in molecular machines, it is necessary to prepare systems in which it is possible to precisely control the molecular motion (e.g., the ability to start and stop the shuttling process) and the location of the macrocyclic components in relation to the dumbbell-shaped component. Two methods have been reported previously for

[a] N.-C. Chen, Y.-H. Liu, Prof. S.-M. Peng, Prof. S.-H. Chiu

Department of Chemistry

National Taiwan University

No. 1, Sec. 4, Roosevelt Road

Taipei, Taiwan (ROC)

Fax: $(+886)$ 2-3366-1677

E-mail:shchiu@ntu.edu.tw

[b] Prof. C.-C. Lai

Institute of Molecular Biology

National Chung Hsing University and

Department of Medical Genetics

China Medical University Hospita

Taichung, Taiwan (ROC)

Supporting information for this article is available on the WWW

under http://www.chemeurj.org/ or from the author. controlling the migration of interlocked macrocycles between degenerate binding sites: $:^{[4]} 1$ ) by covalently attaching a bulky group at the center of the thread component ${ }^{[5]}$ and 2) by noncovalently dimerizing two molecular shuttles through the addition of $\mathrm{Cu}^{\mathrm{I}}$ ions. ${ }^{[6]}$ However, neither of these methods is suited to readily or reversibly controlling the shuttling motion in situ because covalently attaching a bulky group requires the formation and cleavage of a covalent bond and noncovalently dimerizing two molecular shuttles necessitates the use of an ion-exchange column to remove the complexed $\mathrm{Cu}^{\mathrm{I}}$ ions and restart the shuttling process. ${ }^{[7]}$ Thus, to the best of our knowledge, rotaxanebased systems that exhibit truly selective in situ parking and restarting of the motion of interlocked macrocycles at defined locations along dumbbell-shaped components have yet to be achieved. Herein, we report an easy-to-synthesize molecular shuttle, which incorporates two ionic monopyridinium stations and one 2,2'-bipyridine station on the shaft of the dumbbell-shaped component and a bis- $p$-xylyl[26]crown-6 (BPX26C6) ${ }^{[8]}$ unit as the macrocyclic component. With this system, the BPX26C6 unit can be docked selectively on either the central 2,2'-bipyridine or one of the two terminal pyridinium stations, and subsequently, returned to its shuttling molecular motion through the in situ addition of simple reagents (acid/base or metal ion/metal-ion-complexing ligand pairs). 


\section{Results and Discussion}

Previously, we reported that BPX26C6 is capable of forming pseudorotaxane complexes with monopyridinium ions in solution, which allows the one-pot synthesis of molecular rotaxanes. ${ }^{[8 b]}$ Thus, we proposed that a one-pot reaction of BPX26C6, bulky pyridine derivative $\mathbf{1}^{[9]}$ and dibromide $\mathbf{2}^{[10]}$ would yield a [2]rotaxane in which the BPX26C6 unit could shuttle between the two terminal monopyridinium stations and pass over the 2,2'-bipyridine moiety with each transition. Indeed, we isolated [2] rotaxane $\mathbf{3} \cdot 2 \mathrm{PF}_{6}(27 \%$ yield after ion exchange and column chromatography) from the reaction of 1 (120 mM), 2 (60 mM), and BPX26C6 (90 mM) in $\mathrm{CH}_{3} \mathrm{CN}$ (Scheme 1).

The sharp and simple signals observed in the ${ }^{1} \mathrm{H}$ NMR spectrum (Figure 1a) recorded in $\mathrm{CD}_{3} \mathrm{NO}_{2}$ at $298 \mathrm{~K}$ for 3. $2 \mathrm{PF}_{6}$, in addition to the significant broadening of the pyridinium $\left(\mathrm{H}_{\mathrm{c}}\right.$ and $\left.\mathrm{H}_{\mathrm{d}}\right)$ and adjacent methylene $\left(\mathrm{H}_{\mathrm{e}}\right)$ signals, suggested that the BPX26C6 unit shuttles rapidly between the two monopyridinium stations under these conditions. After cooling the solution to $223 \mathrm{~K}$, the corresponding partial ${ }^{1} \mathrm{H}$ NMR spectrum (Figure $1 \mathrm{f}$ ) displays signals for all of the protons and indicates asymmetry in the dumbbellshaped component (e.g., two signals appear at $\delta=1.32$ and $1.43 \mathrm{ppm}$ for the two pairs of tert-butyl groups), which suggests that under these conditions the BPX26C6 unit shuttles between the two monopyridinium stations sufficiently slowly on the ${ }^{1} \mathrm{H}$ NMR spectroscopy timescale, such that one of the monopyridinium stations is encircled by the macrocycle and the other is not. At $260 \mathrm{~K}$, the signal at $\delta=7.72 \mathrm{ppm}$ in Figure 1a began to split into two signals (Figure 1c) with a limiting frequency difference $(\Delta v)$ of $47.2 \mathrm{~Hz}$ (Figure 1f). Therefore, the rate of shuttling $\left(k_{\mathrm{c}}\right)$ of the macrocycle between the two monopyridinium stations, was $105 \mathrm{~s}^{-1}$, which corresponds to a free energy of activation for the shuttling process $\left(\Delta G_{\mathrm{c}}^{\neq}\right)$of $12.8 \mathrm{kcal} \mathrm{mol}^{-1}$ at a coalescence temperature $\left(T_{\mathrm{c}}\right)$ of $260 \mathrm{~K}$, as derived by using the Eyring equation. ${ }^{[11]}$

We obtained single crystals that were suitable for X-ray crystallographic analysis by vapor diffusion of isopropyl ether into a solution of $3 \cdot 2 \mathrm{PF}_{6}$ in $\mathrm{CH}_{3} \mathrm{CN}$. The solid-state structure of $\mathbf{3}^{2+}$ (Figure 2) shows the interlocked nature of the ion, with the BPX26C6 macrocycle encircling one of the pyridinium stations. ${ }^{[12]}$

As BPX26C6 has a much stronger binding affinity towards doubly protonated 2,2'-bipyridinium ions than towards monopyridinium ions in $\mathrm{CD}_{3} \mathrm{NO}_{2},{ }^{[13]}$ we believed that the addition of a suitable amount of acid would enable us to park the macrocyclic unit on the 2,2'-bipyridinium station in the center of the dumbbell-shaped component (Figure 3 ). Thus, when we added trifluoroacetic acid (TFA; 2 equiv) to a solution of $3 \cdot 2 \mathrm{PF}_{6}$ in $\mathrm{CD}_{3} \mathrm{NO}_{2}$, analysis of the ${ }^{1} \mathrm{H} \mathrm{NMR}$ spectrum revealed sharp signals for the pyridinium moieties and their adjacent methylene groups (Figure 4b). In comparison with the spectrum of the protonated free dumbbellshaped component $\left(\mathbf{4 H}_{2}{ }^{4+}\right.$; Figure $\left.4 \mathrm{~d}\right)$, the signals of the 2,2'-bipyridinium aromatic protons $\left(\mathrm{H}_{\mathrm{f}}\right.$ and $\left.\mathrm{H}_{\mathrm{g}}\right)$ of the doubly protonated molecular shuttle $\left(3 \mathrm{H}_{2}{ }^{4+}\right)$ were significantly shifted upfield, but the signals of the monopyridinium protons were relatively unchanged, which suggested that the macrocyclic unit BPX26C6 did indeed preferentially encircle the protonated $2,2^{\prime}$-bipyridinium station in the center of the [2] rotaxane. Subsequent addition of $\mathrm{Et}_{3} \mathrm{~N}$ (2 equiv) to this mixture gave a ${ }^{1} \mathrm{H}$ NMR spectrum (Figure 4c) that was similar to that of the original solution of $3 \cdot 2 \mathrm{PF}_{6}$ (Figure $4 \mathrm{a}$ ), which implied that dynamic movement of the BPX26C6 unit between the two terminal monopyridinium stations had been restored. Thus, [2]rotaxane $3 \cdot 2 \mathrm{PF}_{6}$ behaves as an acid/base-controlled molecular shuttle in solution $;^{[14]}$ the interlocked BPX26C6 macrocycle can be parked selectively at the central 2,2'-bipyridinium station on the dumbbell-shaped component (in $3 \mathrm{H}_{2}{ }^{4+}$ obtained by the addition of TFA) or it can 


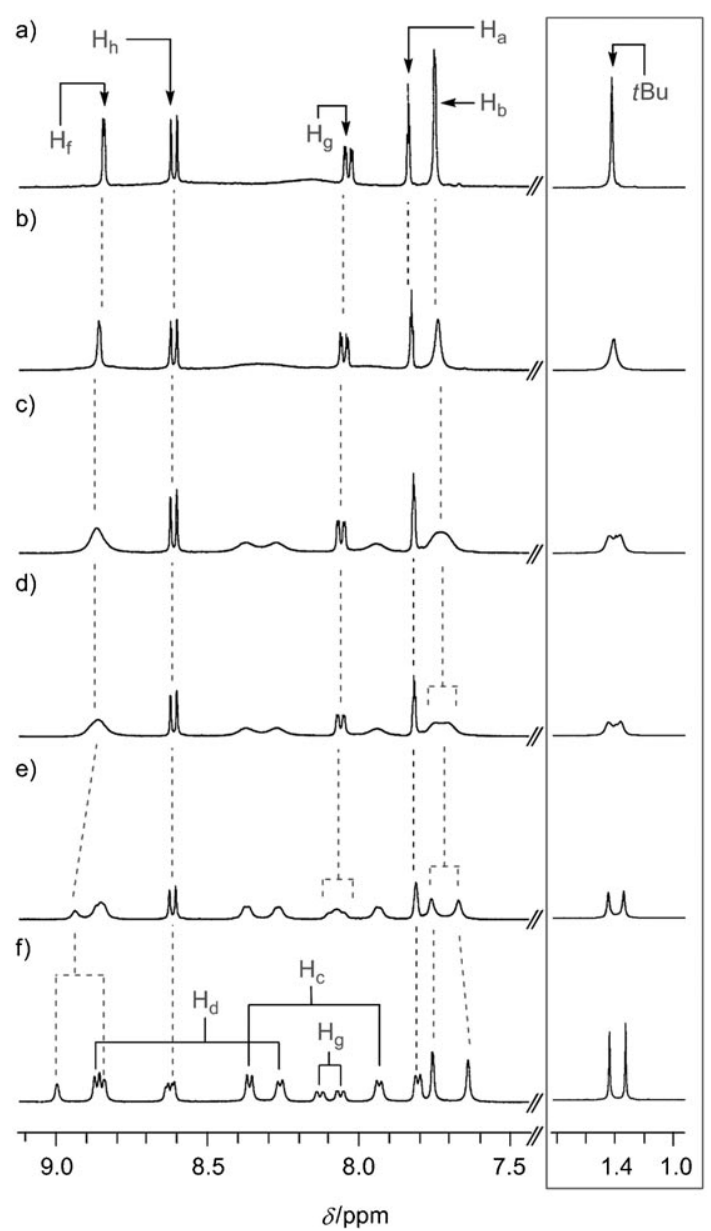

Figure 1. Partial ${ }^{1} \mathrm{H}$ NMR spectra $\left(400 \mathrm{MHz}, \mathrm{CD}_{3} \mathrm{NO}_{2}\right)$ of $\mathbf{3} \cdot 2 \mathrm{PF}_{6}$ recorded at a) 298 , b) 273 , c) 260 , d) 258 , e) 243 , and f) $223 \mathrm{~K}$.

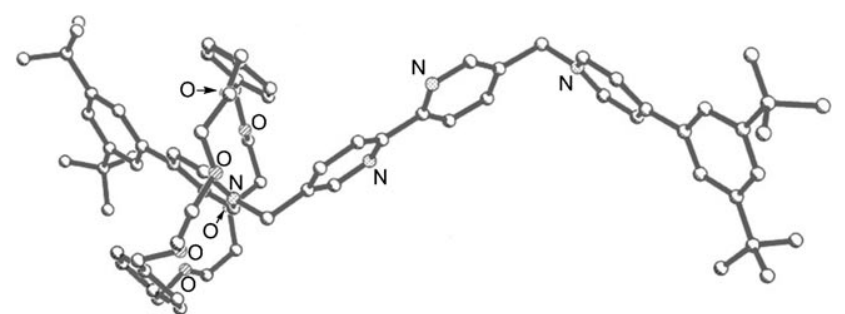

Figure 2. Ball-and-stick representation of the solid-state structure of $[3]^{2+}$.

move freely and reversibly between the two terminal monopyridinium stations (in the deprotonated form $\left(3^{2+}\right)$ obtained by the addition of $\mathrm{Et}_{3} \mathrm{~N}$ ).

As a result of the small size of BPX26C6, we believed that the coordination of a suitable metal ion (and, more importantly, its associated ligands) to the central 2,2'-bipyridine station would stop the shuttling of the macrocycle by forcing it to reside at one of the terminal monopyridinium stations (Figure 3). The addition of $\mathrm{Zn}(\mathrm{OAc})_{2}$ to a solution of $3 \cdot 2 \mathrm{PF}_{6}$ in $\mathrm{CD}_{3} \mathrm{NO}_{2}$ caused dramatic changes to the ${ }^{1} \mathrm{H}$ NMR spectrum, which now displays sets of signals for

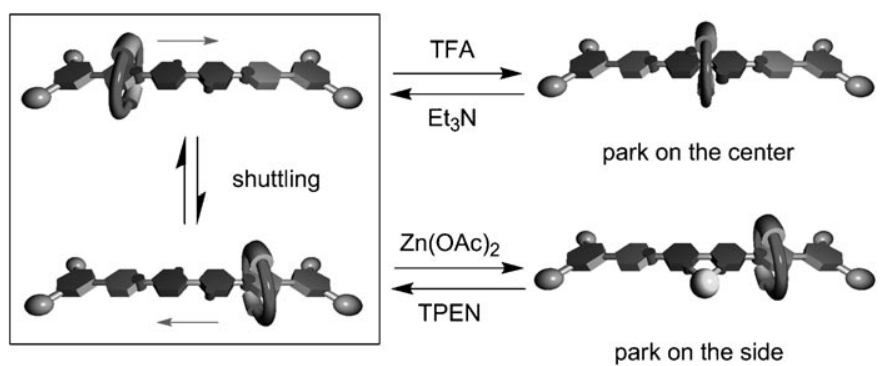

Figure 3. Cartoon representation of the selective docking of the macrocyclic component at different stations along the dumbbell-shaped component of 3.2 $\mathrm{PF}_{6}$.

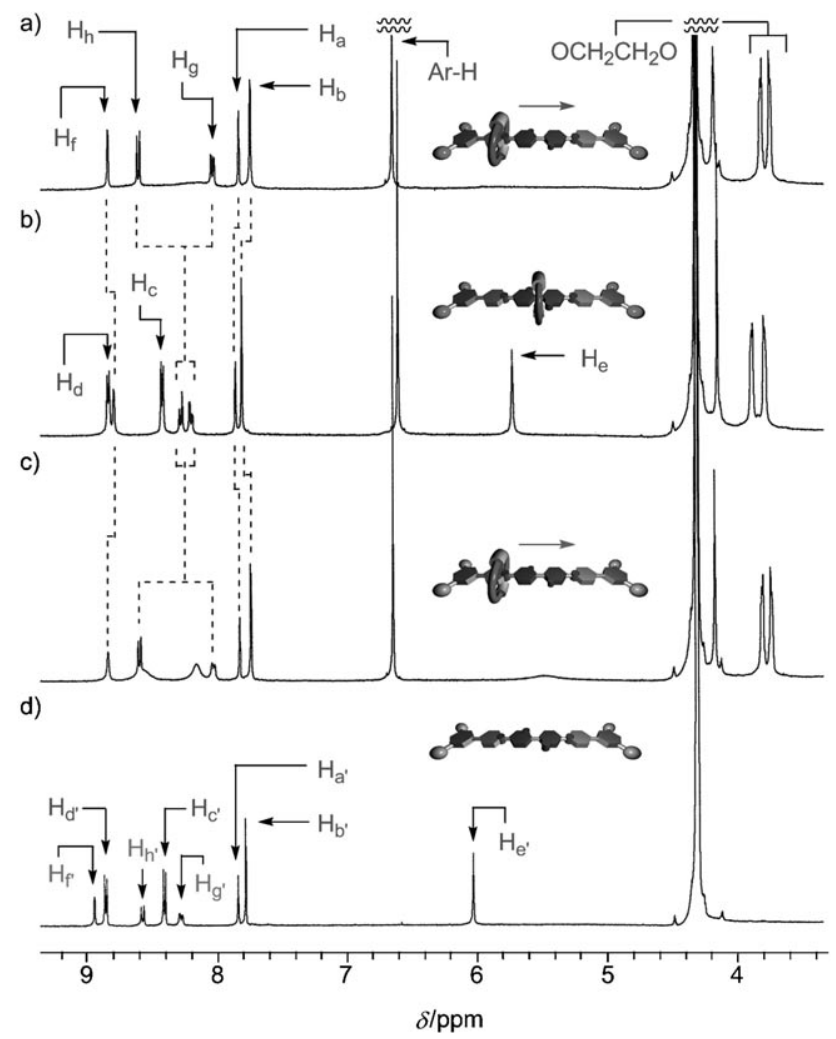

Figure 4. Partial ${ }^{1} \mathrm{H}$ NMR spectra $\left(400 \mathrm{MHz}, \mathrm{CD}_{3} \mathrm{NO}_{2}, \quad 298 \mathrm{~K}\right)$ of a) 3.2 $\mathrm{PF}_{6}$, b) 3.2 $\mathrm{PF}_{6}+\mathrm{TFA}$ (2 equiv), c) solution b) after addition of $\mathrm{Et}_{3} \mathrm{~N}$ ( 2 equiv), and d) free dumbbell-shaped component $4 \cdot 2 \mathrm{PF}_{6}+$ TFA (1:2).

each of the two monopyridinium moieties and their adjacent methylene protons (Figure 5b).$^{[15]}$ The signals at $\delta=5.15$ and $6.08 \mathrm{ppm}$ for the respective pairs of $\mathrm{H}_{\mathrm{e}}$ protons suggest that the dumbbell-shaped component exhibits the asymmetry associated with the BPX26C6 unit selectively encircling just one of the monopyridinium stations, that is, the shuttling process slows considerably after the addition of $\mathrm{Zn}(\mathrm{OAc})_{2}$. To remove the coordinated metal ion from the 2,2'-bipyridine unit, we added tetrapyridineethylenediamine (TPEN) ${ }^{[16]}$ which strongly binds $\mathrm{Zn}^{2+}$ ions, to the solution. The resulting ${ }^{1} \mathrm{H}$ NMR spectrum (Figure $5 \mathrm{c}$ ) is similar to that of $3 \cdot 2 \mathrm{PF}_{6}$ (Figure 5a), which suggests that the $\mathrm{Zn}^{2+}$ ion is no longer chelated to the dumbbell-shaped component 


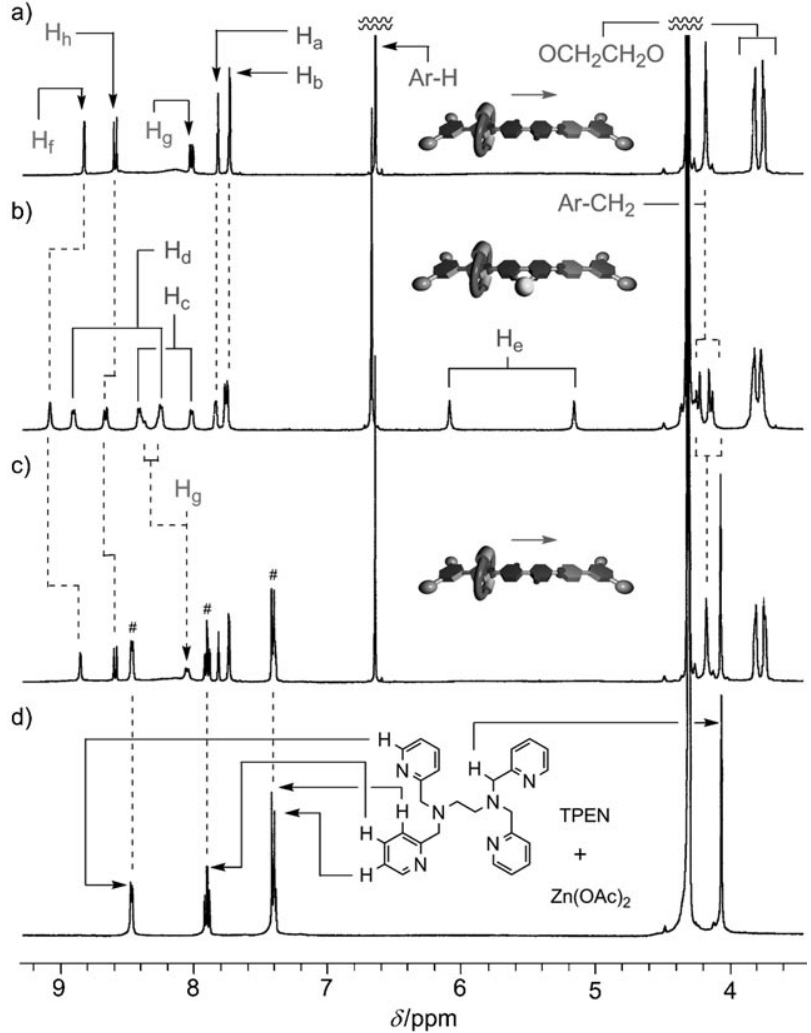

Figure 5. Partial ${ }^{1} \mathrm{H}$ NMR spectra $\left(400 \mathrm{MHz}, \quad \mathrm{CD}_{3} \mathrm{NO}_{2}, \quad 298 \mathrm{~K}\right)$ of a) $3 \cdot 2 \mathrm{PF}_{6}$, b) 3.2 $\mathrm{PF}_{6}+\mathrm{Zn}(\mathrm{OAc})_{2}(1$ equiv), c) solution b) after addition of TPEN (1 equiv), and d) TPEN $+\mathrm{Zn}(\mathrm{OAc})_{2}(1: 1)$. \#: Signals from $[\mathrm{Zn}]^{2+}$ complexed TPEN.

and that the initial molecular shuttling motion is restored. Thus, the sequential addition of $\mathrm{Zn}(\mathrm{OAc})_{2}$ and TPEN to a solution of $3 \cdot 2 \mathrm{PF}_{6}$ in $\mathrm{CD}_{3} \mathrm{NO}_{2}$ leads to a reversible process of initial selective docking of the macrocyclic unit onto one of the terminal monopyridinium stations of the dumbbellshaped component and subsequent regeneration of the original shuttling motion between the two monopyridinium stations. ${ }^{[17]}$

\section{Conclusion}

We have demonstrated that the macrocyclic component of 3. $2 \mathrm{PF}_{6}$ can be parked selectively at either the central $2,2^{\prime}$-bipyridinium station or one of the two terminal monopyridinium stations by the addition of TFA or $\mathrm{Zn}(\mathrm{OAc})_{2}$, respectively. The original shuttling state was then recovered by the addition of a complementary reagent $\left(\mathrm{Et}_{3} \mathrm{~N}\right.$ or TPEN, respectively), thus $3 \cdot 2 \mathrm{PF}_{6}$ mimics the behavior of a molecular machine in which the reversible molecular motion can be stopped and restarted at will. These three discrete and identifiable states of $3 \cdot 2 \mathrm{PF}_{6}$ suggest that it has the potential for applications as a molecular switch, a molecular logic gate, or a molecular sensor, each of which is currently under investigation in our laboratory.

\section{Experimental Section}

General: All glassware, stirrer bars, syringes, and needles were either oven- or flame-dried prior to use. All reagents, unless otherwise indicated, were obtained from commercial sources. Anhydrous $\mathrm{CH}_{2} \mathrm{Cl}_{2}$ and $\mathrm{MeCN}$ were prepared by distillation over $\mathrm{CaH}_{2}$ under $\mathrm{N}_{2}$. Reactions were conducted under either $\mathrm{N}_{2}$ or Ar. Thin-layer chromatography (TLC) was performed by using Merck $0.25 \mathrm{~mm}$ silica gel (Merck Art. 5715). Column chromatography was performed by using Kieselgel 60 (Merck, 70-230 mesh). Melting points were determined by using a Fargo MP-2D melting point apparatus. For the ${ }^{1} \mathrm{H}$ NMR spectroscopic analyses, the deuterated solvent was used as the lock and an internal standard was provided by either the solvent's residual protons or TMS. Chemical shifts are reported in parts per million (ppm). Multiplicities are given as s (singlet), d (doublet), t (triplet), q (quartet), and m (multiple).

X-Ray crystallographic analysis: CCDC $665821\left(3.2 \mathrm{PF}_{6}\right)$ contains the supplementary crystallographic data for this paper. These data can be obtained free of charge from The Cambridge Crystallographic Data Centre via www.ccdc.cam.ac.uk/data_request/cif.

[2]Rotaxane 3.2 $\mathbf{P F}_{6}$ : A mixture of 3,5-di-tert-butylbenzyl bromide (169 mg, $\quad 0.6 \mathrm{mmol}), \quad 5,5^{\prime}$-bis(bromomethyl)-2,2'-bipyridine $\quad(101 \mathrm{mg}$, $0.3 \mathrm{mmol}$ ), and BPX26C6 (186 mg, $0.45 \mathrm{mmol})$ in $\mathrm{CH}_{3} \mathrm{CN}(0.5 \mathrm{~mL})$ was stirred for $3 \mathrm{~d}$ at ambient temperature. After the solvent had been removed under reduced pressure, the residue was washed with diethyl ether $(5 \mathrm{~mL})$, suspended in $\mathrm{MeCN}(2 \mathrm{~mL})$, and then filtered. The solid was collected for further isolation of dumbbell $4 \cdot 2 \mathrm{PF}_{6}$ (see below). Saturated aqueous $\mathrm{NH}_{4} \mathrm{PF}_{6}(10 \mathrm{~mL})$ was added to the filtrate and the organic solvent was evaporated under reduced pressure. The precipitate was collected, washed with $\mathrm{H}_{2} \mathrm{O}(20 \mathrm{~mL})$, and purified by column chromatography $\left(\mathrm{SiO}_{2} ; \mathrm{CH}_{2} \mathrm{Cl}_{2} / \mathrm{MeOH}, 98: 2\right)$ to afford $3 \cdot 2 \mathrm{PF}_{6}$ as a white solid $(113 \mathrm{mg}, 27 \%)$. As a result of shuttling of the macrocycle, the signals of the pyridinium and adjacent methylene protons were broadened severly. M.p. $>235^{\circ} \mathrm{C}$ decomp; ${ }^{1} \mathrm{H}$ NMR $\left(400 \mathrm{MHz}, \mathrm{CD}_{3} \mathrm{CN}, 298 \mathrm{~K}\right): \delta=1.43$ (s, $36 \mathrm{H}), 3.66-3.80(\mathrm{~m}, 16 \mathrm{H}), 4.10(\mathrm{~s}, 8 \mathrm{H}), 6.52(\mathrm{~s}, 8 \mathrm{H}), 7.65(\mathrm{~s}, 4 \mathrm{H}), 7.75(\mathrm{t}$, $J=1.2 \mathrm{~Hz}, 2 \mathrm{H}), 8.00(\mathrm{~d}, J=8 \mathrm{~Hz}, 2 \mathrm{H}), 8.58(\mathrm{~d}, J=8 \mathrm{~Hz}, 2 \mathrm{H}), 8.80 \mathrm{ppm}$ $(\mathrm{s}, 2 \mathrm{H}) ;{ }^{13} \mathrm{C}$ NMR $\left(100 \mathrm{MHz}, \mathrm{CD}_{3} \mathrm{CN}, 298 \mathrm{~K}\right): \delta=31.4,35.7,60.8,70.5$, $71.3,73.3,121.6,122.7,125.9,126.7,127.7,128.2,130.1,133.4,136.9$, $138.8,143.9,150.0,152.3,155.3 \mathrm{ppm}$; HRMS (ESI): $\mathrm{m} / \mathrm{z}$ : calcd for $\left[3 \cdot \mathrm{PF}_{6}\right]^{+}:$1277.6653; found: $1277.6767 ; \mathrm{m} / \mathrm{z}$ : calcd for $[3]^{2+}: 566.3503$; found: 566.3518 .

4.2 $\mathbf{P F}_{6}$ : The precipitate that was collected from the filtration process described above was dissolved in $\mathrm{MeOH}(2 \mathrm{~mL})$ and then saturated aqueous $\mathrm{NH}_{4} \mathrm{PF}_{6}(10 \mathrm{~mL})$ was added. After the organic solvent had been removed under reduced pressure, the precipitate was collected and washed with $\mathrm{H}_{2} \mathrm{O}(20 \mathrm{~mL})$ to yield $\mathbf{4} \cdot 2 \mathrm{PF}_{6}$ as a pink solid $(56 \mathrm{mg}, 19 \%)$. M.p. $>175{ }^{\circ} \mathrm{C}$ decomp; ${ }^{1} \mathrm{H}$ NMR $\left(400 \mathrm{MHz}, \mathrm{CD}_{3} \mathrm{CN}\right): \delta=1.38(\mathrm{~s}, 36 \mathrm{H}), 5.78(\mathrm{~s}$, $4 \mathrm{H}), 7.70(\mathrm{~d}, J=2 \mathrm{~Hz}, 4 \mathrm{H}), 7.76(\mathrm{t}, J=2 \mathrm{~Hz}, 2 \mathrm{H}), 7.96(\mathrm{dd}, J=8,2 \mathrm{~Hz}$, $2 \mathrm{H}), 8.32(\mathrm{~d}, J=7 \mathrm{~Hz}, 4 \mathrm{H}), 8.50(\mathrm{~d}, J=8 \mathrm{~Hz}, 2 \mathrm{H}), 8.75(\mathrm{~d}, J=8 \mathrm{~Hz}, 4 \mathrm{H})$, $8.77 \mathrm{ppm}(\mathrm{d}, J=2 \mathrm{~Hz}, 2 \mathrm{H}) ;{ }^{13} \mathrm{C}$ NMR $\left(100 \mathrm{MHz}, \mathrm{CD}_{3} \mathrm{CN}\right): \delta=31.3,35.7$, $61.4,121.5,122.8,125.9,127.1,130.0,133.5,138.0,144.2,149.7,152.7$, 156.0, $157.9 \mathrm{ppm}$; HRMS (ESI): $\mathrm{m} / z$ : calcd for $\left[4 \cdot \mathrm{PF}_{6}\right]^{+}: 861.4454$; found: $861.4384 ; \mathrm{m} / \mathrm{z}$ : calcd for $[4]^{2+}: 358.2404$; found: 358.2335 .

\section{Acknowledgement}

This study was supported by the National Science Council, Taiwan (NSC95-2113M-002-016-MY3).

[1] a) Molecular Electronics: Science and Technology (Eds.: A. Aviram, M. Ratner), New York Academy of Sciences, New York, 1998; b) C. P. Collier, G. Mattersteig, E. W. Wong, Y. Luo, K. Beverly, J. Sampaio, F. M. Raymo, J. F. Stoddart, J. R. Heath, Science 2000, 289, 1172-1175; c) H. Yu, Y. Luo, K. Beverly, J. F. Stoddart, H.-R. Tseng, J. R. Heath, Angew. Chem. 2003, 115, 5884-5889; Angew. Chem. Int. Ed. 2003, 42, 5706-5711; d) A. H. Flood, R. J. A. Ramir- 
ez, W.-Q. Deng, R. P. Muller, W. A. Goddard III, J. F. Stoddart, Aust. J. Chem. 2004, 57, 301-322.

[2] a) P.-L. Anelli, N. Spencer, J. F. Stoddart, J. Am. Chem. Soc. 1991, 113, 5131-5133; b) P.-L. Anelli, M. Asakawa, P. R. Ashton, R. A. Bissell, G. Clavier, R. Gorski, A. E. Kaifer, S. J. Langford, G. Mattersteig, S. Menzer, D. Philp, A. M. Z. Slawin, N. Spencer, J. F. Stoddart, M. S. Tolley, D. J. Williams, Chem. Eur. J. 1997, 3, 1113-1135; c) J. Cao, M. C. T. Fyfe, J. F. Stoddart, G. R. L. Cousins, P. T. Glink, J. Org. Chem. 2000, 65, 1937-1946; d) V. Bermudez, N. Capron, T. Gase, F. G. Gatti, F. Kajzar, D. A. Leigh, F. Zerbetto, S. Zhang, Nature 2000, 406, 608-611; e) S. J. Loeb, J. A. Wisner, Chem. Commun. 2000, 1939-1940; f) D. A. Leigh, A. Troisi, F. Zerbetto, Angew. Chem. 2000, 112, 358-361; Angew. Chem. Int. Ed. 2000, 39, 350-353; g) M. Belohradsky, A. M. Elizarov, J. F. Stoddart, Collect. Czech. Chem. Commun. 2002, 67, 1719-1728.

[3] The dynamic data were estimated by using the coalescence method; see: I. O. Sutherland, Annu. Rep. NMR Spectrosc. 1971, 4, 71-235.

[4] It has been demonstrated that the shuttling process could be initiated by the addition of a polar solvent that disrupts the hydrogenbonding interactions between the macrocycle and the dumbbell component of a glycylglycine rotaxane in a less-polar solvent, but this procedure seems to be irreversible; see: D. A. Leigh, A. Murphy, M. J. Smart, A. M. Z. Slawin, Angew. Chem. 1997, 109, 752-756; Angew. Chem. Int. Ed. Engl. 1997, 36, 728-732.

[5] a) A. S. Lane, D. A. Leigh, A. Murphy, J. Am. Chem. Soc. 1997, 119, 11092-11093; there are several examples of methods to covalently block the movement of a macrocycle along a rotaxane's thread; see: b) J. S. Hannam, S. M. Lacy, D. A. Leigh, C. G. Saiz, A. M. Z. Slawin, S. G. Stitchell, Angew. Chem. 2004, 116, 3322-3326; Angew. Chem. Int. Ed. 2004, 43, 3260-3264; c) H. Kawai, T. Umehara, K. Fujiwara, T. Tsuji, T. Suzuki, Angew. Chem. 2006, 118, 4387-4392; Angew. Chem. Int. Ed. 2006, 45, 4281-4286; d) M. N. Chatterjee, E. R. Kay, D. A. Leigh, J. Am. Chem. Soc. 2006, 128, 4058-4073.

[6] L. Jiang, J. Okano, A. Orita, J. Otera, Angew. Chem. 2004, 116, 2173-2176; Angew. Chem. Int. Ed. 2004, 43, 2121-2124.

[7] The process of using an ion-exchange resin to remove the $\mathrm{Cu}^{\mathrm{I}}$ ions takes more than $10 \mathrm{~min}$ to perform; see reference [6].

[8] a) P.-N. Cheng, P.-Y. Huang, W.-S. Li, S.-H. Ueng, W.-C. Hung, Y.-H Liu, C.-C. Lai, S.-M. Peng, I. Chao, S.-H. Chiu, J. Org. Chem. 2006, 71, 2373-2375; b) P.-N. Cheng, C.-F. Lin, Y.-H. Liu, C.-C. Lai, S.-M. Peng, S.-H. Chiu, Org. Lett. 2006, 8, 435-438.

[9] C.-F. Lin, C.-C. Lai, Y.-H. Liu, S.-M. Peng, S.-H. Chiu, Chem. Eur. J. 2007, 13, 4350-4355
[10] U. S. Schubert, C. Eschbaumer, G. Hochwimmer, Synthesis 1999 $779-782$.

[11] The relationship $\Delta G_{\mathrm{c}}^{\neq}=-R T_{\mathrm{c}} \ln \left(k_{\mathrm{c}} h / k_{\mathrm{B}} T_{\mathrm{c}}\right)$, in which $R, h$, and $k_{\mathrm{B}}$ correspond to the gas, Planck, and Boltzmann constants, respectively, was used to obtain values for the free energy of activation for shuttling $\left(\Delta G_{\mathrm{c}}^{\neq}\right)$at the coalescence temperature $\left(T_{\mathrm{c}}\right)$. By using the tertbutyl groups as probe protons, the values of $\Delta v, T_{\mathrm{c}}$, and $k_{\mathrm{c}}$ were determined to be $44.8 \mathrm{~Hz}, 264 \mathrm{~K}$, and $100 \mathrm{~s}^{-1}$, respectively, which corresponds to a $\Delta G_{\mathrm{c}}^{\neq}$value of $13.0 \mathrm{kcal} \mathrm{mol}^{-1}$ and is quite close to the value we obtained by using proton $\mathrm{H}_{\mathrm{b}}$ as the probe.

[12] Crystal data for 3. $\mathrm{H}_{2} \mathrm{O} \cdot 2 \mathrm{PF}_{6}:\left[\mathrm{C}_{74} \mathrm{H}_{94} \mathrm{O}_{7} \mathrm{~N}_{4}\right]\left[\mathrm{PF}_{6}\right]_{2} ; M_{\mathrm{r}}=1441.47$; triclinic; space group $P \overline{1} ; \quad a=12.1307(2), \quad b=12.8642(1), \quad c=$ 27.3374(4) $\AA ; \quad V=3867.49(9) \AA^{3} ; \quad \rho_{\text {calcd }}=1.238 \mathrm{~g} \mathrm{~cm}^{-3} ; \quad \mu\left(\mathrm{Mo}_{\mathrm{K} \alpha}\right)=$ $0.137 \mathrm{~mm}^{-1} ; T=295$ (2) $\mathrm{K}$; colorless prisms; 13556 independent measured reflections; $F^{2}$ refinement; $R_{1}=0.0988, w R_{2}=0.2862$.

[13] The association constant, $K_{\mathrm{a}}$, for the complexation of BPX26C6 to 4-methylpyridinium hexafluorophosphate in $\mathrm{CD}_{3} \mathrm{NO}_{2}$ was determined to be $(17 \pm 5) \mathrm{M}^{-1}$ from the results of an NMR spectroscopy dilution experiment. Previously, we reported a $K_{\mathrm{a}}$ value of $(130 \pm$ 15) $\mathrm{M}^{-1}$ for the complexation between BPX26C6 and 2,2'-bipyridinium bis(hexafluorophosphate) in the same solvent; see: N.-C. Chen, P.-Y. Huang, C.-C. Lai, Y.-H. Liu, S.-M. Peng, S.-H. Chiu, Chem. Commun. 2007, 4122-4124.

[14] Several nondegenerate [2] rotaxanes that behave as acid/base-controlled molecular switches are known; see: a) J. W. Lee, K. Kim, K Kim, Chem. Commun. 2001, 1042-1043; b) A. M. Elizarov, S.-H Chiu, J. F. Stoddart, J. Org. Chem. 2002, 67, 9175-9181; c) J. D Badjic, C. M. Ronconi, J. F. Stoddart, V. Balzani, S. Silvi, A. Credi, J. Am. Chem. Soc. 2006, 128, 1489-1499.

[15] The addition of $\mathrm{Zn}(\mathrm{OAc})_{2}$ (0.5 equiv) to a solution of $\mathbf{3} \cdot 2 \mathrm{PF}_{6}$ in $\mathrm{CD}_{3} \mathrm{NO}_{2}$ gave a $1: 1$ mixture of free and $[\mathrm{Zn}]^{2+}$-complexed $3 \cdot 2 \mathrm{PF}_{6}$, based on analysis of the ${ }^{1} \mathrm{H}$ NMR spectrum, which suggests that 3. $2 \mathrm{PF}_{6}$ does not dimerize under these conditions.

[16] For details of the binding of $\mathrm{Zn}^{2+}$ ions by TPEN, see: a) E. Kawabata, K. Kikuchi, Y. Urano, H. Kojima, A. Odani, T. Nagano, J. Am. Chem. Soc. 2005, 127, 818-819; b) C. A. Blindauer, M. T. Razi, S. Parsons, P. J. Sadler, Polyhedron 2006, 25, 513-520.

[17] The use of metal coordination to block the passage of the macrocycle in a rotaxane has been reported previously; see: D. A. Leigh, P. J. Lusby, A. M. Z. Slawin, D. B. Walker, Angew. Chem. 2005, 117, 4633-4640; Angew. Chem. Int. Ed. 2005, 44, 4557-4564.

Received: November 26, 2007 Published online: January 22, 2008 